\title{
Stable Isotope Analysis of Human Hair and Nail Samples: The Effects of Storage on Samples
}

\begin{abstract}
When submitting samples for analysis, maintaining sample integrity is essential. Appropriate packaging must be used to prevent damage, contamination or loss of sample. This is particularly important for stable isotope analysis by isotope ratio mass spectrometry as this technique is capable of detecting subtle differences in isotopic composition with great precision. In a novel study, scalp hair and fingernail samples were placed in five different types of packaging, routinely used in forensic laboratories and stored for 6 weeks and 6 months. Samples were subsequently cleaned and submitted for ${ }^{13} \mathrm{C} /{ }^{12} \mathrm{C},{ }^{15} \mathrm{~N} /{ }^{14} \mathrm{~N},{ }^{2} \mathrm{H} /{ }^{1} \mathrm{H}$ and ${ }^{18} \mathrm{O} /{ }^{16} \mathrm{O}$ analysis. Results from ${ }^{13} \mathrm{C}$ analysis indicate that type of packaging can cause slight changes in ${ }^{13} \mathrm{C}$ abundance over time. Differences were noted in the ${ }^{15} \mathrm{~N}$ isotope signatures of both hair and nail samples after 6-week storage, but not after 6 months. This apparent discrepancy could be a result of the packaging not being properly sealed in the 6 weeks study. Fewer differences were noted when analyzing samples for ${ }^{2} \mathrm{H}$ and ${ }^{18} \mathrm{O}$ abundance.
\end{abstract}

KEYWORDS: forensic science, isotope ratio mass spectrometry, hair, nails, storage, plasticizers, coatings

Isotope ratio mass spectrometry (IRMS) is becoming an established technique in the forensic profiling of samples including drugs, paints, and food products (1-5). With an increasing number of laboratories and institutes investing in new instruments the need to fully validate the method is now even greater than before. Several studies have demonstrated its potential as a tool for determining the place of origin of living humans, unidentified human remains, and the identification of disaster victims (6-10). In order to apply this technique in forensic investigations, factors that may potentially have a detrimental effect on measured isotopic signatures need to be explored.

In any situation where samples are submitted to a laboratory for analysis, maintaining the integrity of the samples is essential. Appropriate packaging and storage containers must be used to prevent contamination, evaporation or damage. This is particularly important when submitting samples for analysis by IRMS as this technique is capable of detecting minute changes in isotopic abundance. This communication investigates the effects of different types of packaging on isotopic sample integrity of hair and nail samples submitted for isotope analysis. Whilst actual packaging materials have been analyzed using IRMS $(11,12)$, to the best of the author's knowledge, no previous work has been carried out to investigate the effects of packaging itself on samples submitted for stable isotope analysis.

Once collected, samples are usually stored for varying amounts of time depending on urgency, resources available, etc. However, even after a case has been closed, samples are still retained for a period of time to allow for appeals and re-examination. For this reason, it is important samples are securely stored in containers that

\footnotetext{
${ }^{1}$ Environmental Forensics and Human Health, Environmental Engineering Research Centre, Queen's University Belfast, Belfast BT9 5AG, United Kingdom.

Preliminary data from this study have been presented in the form of a poster at the 2005 Forensic Isotope Ratio Mass Spectrometry network (FIRMS), Brands Hatch, United Kingdom.

Received 7 May 2006; and in revised form 15 Oct. 2006; accepted 24 June 2007.
}

will not compromise sample integrity-either through cross-contamination or leaching of substances from the packaging material itself.

Plasticizers found in plastic evidence bags, for example, could contribute to the isotope values measured. Modern plasticizers are manmade organic chemicals such as adipates and phthalates, which are added to a material to make it more pliable (13). Problems arising from the leaching of plasticizers have been reported for di(2ethyl-hexyl) phthalate (DEHP), a plasticizer found in PVC products such as medical blood bags. Jaegar and Rubin (14) found that DEHP leached into stored human blood. As DEHP is not covalently bonded to PVC it was found that it could migrate out of the plastic. Although subsequent studies (15) found that the effect was not harmful if the blood was stored for a limited period of time, this finding demonstrates the fact that the certain packaging materials can be detrimental to the sample being stored.

This study has been designed to determine whether or not certain types of packaging permit the entry of airborne particles into the container or traps moisture inside the packaging which could affect the integrity of the sample, and thus alter the isotope profile of the sample. In addition, the study hopes to establish whether there is any evidence of a change in the isotopic profile of samples because of an interaction between the packaging container and its contents. For example, water vapor or other chemicals may be absorbed onto the surface of the sample or migrate into the sample itself.

\section{Materials and Methods}

Having obtained ethical approval from the Office for Research Ethics Committees Northern Ireland (ORECNI), samples of scalp hair and fingernails (hereafter referred to as hair and nail) from the same subject were placed into each of the following packages: plastic self-seal bags, plastic eppendorff tubes, paper envelopes, pieces of tin foil, and crimp-sealed glass vials. Only one of each type of container was used at this time because the initial idea was to establish whether or not differences existed between different storage containers. Samples were stored for a period of 6 weeks in 
a cool, dry laboratory cupboard. The same experiment was repeated a month later using samples collected from the same subject, but in this instance they were stored for a period of 6 months.

Ideally, samples for both the 6-week and the 6-month experiment should have been collected from the same subject at the same time. Unfortunately, it was not possible to collect the amount of material required to satisfy the needs of comprehensive isotope analysis $\left({ }^{13} \mathrm{C} /{ }^{12} \mathrm{C},{ }^{15} \mathrm{~N} /{ }^{14} \mathrm{~N},{ }^{2} \mathrm{H} /{ }^{1} \mathrm{H}\right.$, and $\left.{ }^{18} \mathrm{O} /{ }^{16} \mathrm{O}\right)$ and both storage experiments in one single collection. However, the subject whose hair and nails were collected for this study had not traveled or changed his diet during the sampling interval. Previous research by our group (6) has demonstrated the relatively low degree of intra-individual natural variability in stable isotope composition of hair and nail samples. The natural variation for $\delta^{13} \mathrm{C}$ and $\delta^{15} \mathrm{~N}$ values from hair and nails of an individual residing in one location over a period of 6 months was $<1.5 \%$ whilst the natural variation of $\delta^{18} \mathrm{O}$ and $\delta^{2} \mathrm{H}$ values was $<3 \%$ and $10 \%$, respectively.

\section{Cleaning of Samples}

After 6-week/6-month storage, all samples were cleaned according to a published standard procedure (8). In order to overcome problems regarding static electricity, once cleaned, all samples were ground using a SPEX CertiPrep cryogenic freezer/mill (blen Creston Ltd, Stanmae, Middlesex, UK) using stainless steel vials and impactors. Samples were ground using the standard programme setting of a 15-minute precool followed by three grinding cycles of $2 \mathrm{~min}$ each at a rate of 10 , where rate refers to the number of impacts per second. There was a 2-minute cooling period between each grinding cycle. Ground samples were easier to weighed out in small amounts into tin/silver capsules and the loss of sample during grinding was minimal $(<10 \%)$. Results of comparative isotope analysis of ground versus unground samples were not significantly different, but grinding samples improved reproducibility of triplicate analysis, probably because of improved homogeneity. The cryogenic mill also permits the fine grinding of samples without the heat build-up generated by conventional grinding methods-thus avoiding potential isotopic fractionation through temperature changes.

Following grinding, samples were placed in glass vials, sealed and stored for a minimum of 7 days in a desiccator containing phosphorous pentoxide, to remove residual moisture traces from the samples. This was particularly important for hydrogen $(\mathrm{H})$ and oxygen $(\mathrm{O})$ isotope analysis as it is known that $\mathrm{H}$ and $\mathrm{O}$ exchange between moisture and exchangeable $\mathrm{H}$ 's and $\mathrm{OH}$ 's can have a significant effect on the measured isotope values of samples (16). All samples were exposed to the same environment after collection to ensure labile $\mathrm{H}$-atoms prone to exchange would all reflect the same ${ }^{2} \mathrm{H}$ level, i.e., that of ambient humidity in our laboratory. Samples were therefore analyzed on a "like-for-like" basis, i.e., on the principle of identical treatment (PIT) (16).

Standards and reference materials used in the analysis of the samples were stored in the containers in which they were received from the suppliers, i.e., glass vials. Because these materials provide the means to express measured isotope ratios in values of the internationally used $\delta$-notation (Eq. 1), these materials were not subject of the storage experiment.

\section{Bulk Isotope Analysis by EA-IRMS}

Analysis of ${ }^{13} \mathrm{C}$ and ${ }^{15} \mathrm{~N}$-A Carlo Erba elemental analyzer (CN 1500 ) coupled to an ABCA isotope ratio mass spectrometer (EA-IRMS) (SerCon Ltd., Crewe, U.K.) was used for ${ }^{13} \mathrm{C} /{ }^{12} \mathrm{C}$ and ${ }^{15} \mathrm{~N} /{ }^{14} \mathrm{~N}$ isotope ratio measurement of ground hair and nail samples. Typically, $0.5 \mathrm{mg}$ of sample was weighed into a tin capsule (Elemental Microanalysis) and introduced into the EA by means of a solid autosampler. The EA reactor tubes were selfpacked and comprised of two quartz glass tubes filled with chromium (III) oxide and reduced copper for combustion and reduction, respectively. Combustion and reduction reactor temperature was set to $1000^{\circ} \mathrm{C}$ and $600^{\circ} \mathrm{C}$, respectively, while the postreactor GC column, filled with molecular sieve $5 \AA$, was kept at $80^{\circ} \mathrm{C}$ for separation of evolved $\mathrm{N}_{2}$ and $\mathrm{CO}_{2}$. Data were processed using proprietary software Calisto (SerCon Ltd, Crewe, U.K.). The run time per analysis was $530 \mathrm{sec}$. Measured ${ }^{13} \mathrm{C} /{ }^{12} \mathrm{C}$ and ${ }^{15} \mathrm{~N} /{ }^{14} \mathrm{~N}$ isotope ratios are expressed in the $\delta$-notation in parts per thousand $(\%$ ) (see Eq. 1) relative to the international standards VPDB and AIR, respectively.

$$
\delta(\%)=\left[\frac{R_{\text {Sample }}-R_{\text {Strd }}}{R_{\text {Strd }}}\right] \times 1000
$$

Analysis of ${ }^{2} \mathrm{H}$ and ${ }^{18} \mathrm{O}$-Helium, carbon monoxide and hydrogen of at least $99.999 \%$ purity were purchased from Air Products (Crewe, U.K.) and BOC (Guilford, Surrey, U.K.), respectively. An internationally recognized isotope reference material (IAEA $\mathrm{CH}-7)$ was obtained from the IAEA (Vienna, Austria).

A Thermo Finnigan Delta ${ }^{\text {Plus }}$ XP coupled to a High Temperature Conversion/Elemental Analyzer (TC/EA) (Thermo Electron Corporation, Bremen, Germany) was used for ${ }^{2} \mathrm{H} /{ }^{1} \mathrm{H}$ and ${ }^{18} \mathrm{O} /{ }^{16} \mathrm{O}$ isotope ratio measurement of ground hair and nail samples. Typically, $0.2 \mathrm{mg}$ of sample was weighed into a silver capsule and placed in a desiccator for a week before the samples are introduced into the TC/EA by means of a solid Costech Zero-Blank autosampler (Pelican Scientific Ltd., Alford, U.K.). The reactor tube was self-packed and comprised of an Alsint ${ }^{\mathrm{TM}}$ ceramic tube (Multilab, Newcastle, U.K.), containing a glassy carbon tube (HTW GmbH, Thierhaupten, Germany) filled with glassy carbon granulate, silver, and quartz wool. Reactor tubes were self-packed according to manufacturer's packing recommendation for solid sample analysis. Reactor temperature was set to $1450^{\circ} \mathrm{C}$ while the postreactor $\mathrm{GC}$ column was maintained at $90^{\circ} \mathrm{C}$. Helium pressure was set to 1.45 bars. Data were processed using Isodat NT software, version 2.0 (Thermo Finnigan, Basel, Switzerland). The run time per analysis was $350 \mathrm{sec}$. Measured ${ }^{2} \mathrm{H} /{ }^{1} \mathrm{H}$ and ${ }^{18} \mathrm{O} /{ }^{16} \mathrm{O}$ isotope ratios were expressed as $\delta$-values in parts per thousand $(\%)$ relative to VSMOW.

\section{Isotopic Calibration and Quality Control of EA-IRMS Measurement}

${ }^{13} \mathrm{C} /{ }^{12} \mathrm{C}$ and ${ }^{15} \mathrm{~N} /{ }^{14} \mathrm{~N}$ analysis-Each batch of samples was bracketed by a set of two certified laboratory standards of known isotopic composition. These two standards were leucine $\left(\delta^{13} \mathrm{C}_{\mathrm{VPDB}}=-30.52 \%\right)$ and glycine $\left(\delta^{13} \mathrm{C}_{\mathrm{VPDB}}=-45.54 \%\right.$ oo $)$. At regular intervals, system performance was cross-checked by running these two standards against an international standard, IAEA-CH-6 $\left(\delta^{13} \mathrm{C}_{\mathrm{VPDB}}=-10.4 \%\right.$ oo $)$. Typically, a batch analysis comprised six samples run in triplicate preceded and followed by a set of standards. Such a set consisted of three leucine filled capsules, with the first of these acting as an isotopic reference (REF) and the two other samples acting as additional quality controls (QC1). Two glycine filled capsules follow the leucine standard samples to act as secondary quality controls (QC2). Raw data were blank corrected and calibrated against the REF samples by the proprietary instrument software. If necessary, $\delta$-values were 
drift corrected according to the deviation of the measured $\delta$-value from the known $\delta$-value of the QC standards.

${ }^{2} \mathrm{H} /{ }^{1} \mathrm{H}$ and ${ }^{18} \mathrm{O} /{ }^{16} \mathrm{O}$ Analysis-The working reference gas, $\mathrm{H}_{2}$ was calibrated against V-SMOW using an IAEA standard, IAEA$\mathrm{CH}-7$ polyethylene $\left(\delta^{2} \mathrm{H}_{\mathrm{VSMOW}}=-100.3 \%\right.$ o $)$, as well as a certified laboratory standard coumarin $\left(\delta^{2} \mathrm{H}_{\mathrm{VSMOW}}=+62.56 \%\right)$. The $\mathrm{H}_{3}{ }^{+}$ factor was also calculated; $\mathrm{H}_{3}{ }^{+}$ions are generated by the impact of $\mathrm{H}_{2}{ }^{+}$ions and $\mathrm{H}_{2}$ molecules. As they have the same mass as the ${ }^{1} \mathrm{H}^{2} \mathrm{H}^{+}\left(\mathrm{HD}^{+}\right)$ions their contribution to the ion count of $\mathrm{m} / \mathrm{z}, 3$ has to be accounted and corrected for. The $\mathrm{H}_{3}{ }^{+}$factor was determined on reference $\mathrm{H}_{2}$ gas pulses $\left(\delta^{2} \mathrm{H}_{\mathrm{VSMOW}}=-204.45 \%\right)$ of different signal size and was found to be 3.9. A batch analysis comprised 10 samples run in triplicate, preceded and followed by a set of standards. This set consisted of two in-house standards and three international standards (IAEA-CH-7) as calibration controls at the beginning and end of the set. Four samples containing IAEA-CH-7 and two blank samples are analyzed in the middle of the run, splitting the samples in to two brackets of five samples analyzed in triplicate. Each batch is preceded and followed by a blank capsule. Measured $\delta^{2} \mathrm{H}$-values were normalized according to the method described by Coplen (17) with Z-factors (or "stretch" factors) typically being of the order of 1.02-1.03.

\section{Results and Discussion}

Two storage experiments were carried out, lasting 6 weeks and 6 months, respectively, to ascertain whether the packaging in which samples such as hair and nail are stored interferes with the isotope signature of the sample.
Results of ${ }^{13} \mathrm{C}$ bulk stable isotope analysis after 6-week storage indicate that the type of packaging has no significant bearing on the results obtained (see Fig. 1a). Although the nail sample stored in foil had a slightly more depleted ${ }^{13} \mathrm{C}$-value than the other samples and the sample stored in the self-seal plastic bag had a more enriched $\delta^{13} \mathrm{C}$-value, these differences are within the natural variation expected for an individual living in a fixed location $(1.5 \%$ o $)$. Explanations for these findings may be that the foil was not wrapped tight enough around the sample, allowing the sample to be contaminated. According to the European Aluminium Foil Association and the Aluminium Federation Ltd. (personal communication), standard domestic aluminum foil does not have a coating on its surface, however more specialized foils may have a polymer coating. As this may "rub off" onto the sample being stored it is important that the foil is carefully selected. Similarly, self-seal plastic bags regularly contain plasticizers to keep the product soft and pliable; the presence of these additives may contribute to the isotopic signature of the sample. It was not possible to compare the nail sample stored in an envelope with the remaining samples as it was only analyzed once because of insufficient amount of sample. Bulk ${ }^{13} \mathrm{C}$ isotope analysis of the hair samples indicated that the sample stored in the self-seal plastic bag had a more enriched $\delta^{13} \mathrm{C}$-value than the other samples although the isotopic shift is within the expected range.

Greater differences between the different storage methods are visible when observing the ${ }^{15} \mathrm{~N}$ values after a period of 6 -week storage, as demonstrated in Fig. 1b. The nail samples stored in a glass vial and a plastic self-seal bag had more enriched $\delta^{15} \mathrm{~N}$-value compared to the other samples. In addition, the hair sample stored in the envelope was noticeably more enriched in $\delta^{15} \mathrm{~N}$ than the remaining samples. Although small, these isotope shifts are greater
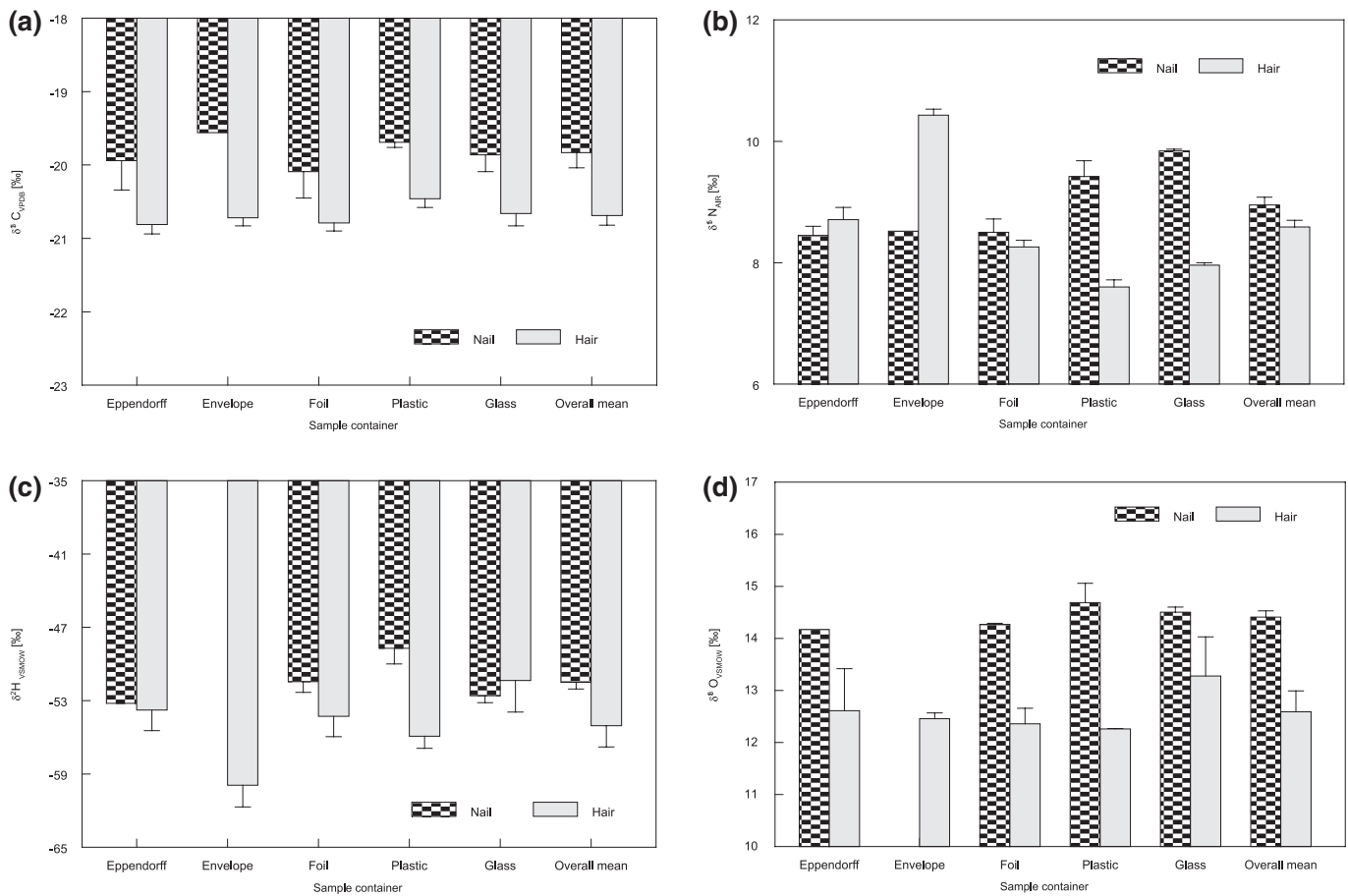

FIG. 1-The effect of packaging on the isotopic composition of hair and nails following 6-week storage. (a) $\delta^{13} \mathrm{C}$ values of hair and nails, (b) $\delta^{15} N$ values of hair and nails, (c) $\delta^{2} H$ values of hair and nails and $(d) \delta^{18} O$ values of hair and nails. Results represent the mean of a triplicate analysis and error bars indicate standard deviation of replicate analyses of the same sample. The natural variation for $\delta^{13} \mathrm{C}$ and $\delta^{15} \mathrm{~N}$ values from hair and nails of an individual residing in one location over a period of 6 months was $<1.5 \%$ whilst the natural variation of $\delta^{18} \mathrm{O}$ and $\delta^{2} \mathrm{H}$ values was $<3 \%$ and $10 \%$, respectively. Because of insufficient sample ${ }^{2} \mathrm{H}$ analysis of the hair sample stored in an envelope was not possible. 

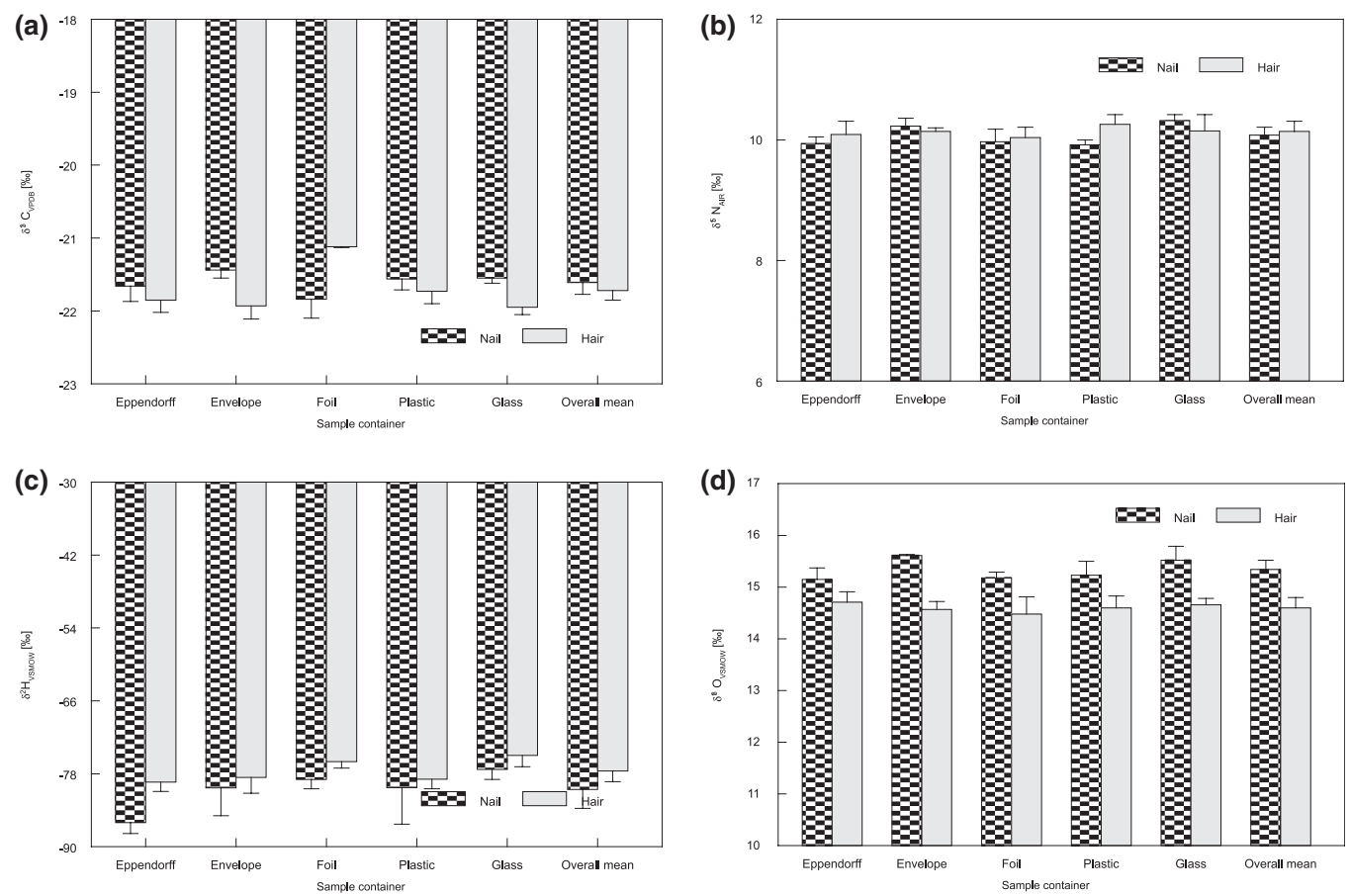

FIG. 2-The effect of packaging on the isotopic composition of hair and nails following 6-month storage. (a) $\delta^{13} \mathrm{C}$ values of hair and nails $(b) \delta^{15} N$ values of hair and nails $(c) \delta^{2} H$ values of hair and nails and $(d) \delta^{18} O$ values of hair and nails. Results represent the mean of a triplicate analysis and error bars indicate standard deviation of replicate analyses of the same sample. The natural variation for $\delta^{13} \mathrm{C}$ and $\delta^{15} \mathrm{~N}$ values from hair and nails of an individual residing in one location over a period of 6 months was $<1.5 \%$ whilst the natural variation of $\delta^{18} \mathrm{O}$ and $\delta^{2} \mathrm{H}$ values was $<3 \%$ and $10^{\circ}$, respectively.

than the variation expected from an individual living in a fixed location $(1.5 \%$ o $)$. As a sample stored within an envelope is not completely isolated from the ambient air as with the other containers, there is the possibility that the sample was exposed to humidity fluctuations and this could be responsible for the unusual result. In addition, the surfaces of some types of paper are coated, often with fine clay, to make it glossier and easier to print on-transfer of this substance to the sample may affect its isotopic signature.

After 6-week storage, the results of ${ }^{2} \mathrm{H}$ analysis showed that all samples had an isotope value within the expected range (Fig. 1c). Due to insufficient sample, ${ }^{2} \mathrm{H}$ analysis of nail stored within an envelope was not possible. As shown in Fig. 1d, the results indicate that there is no difference in the oxygen values obtained for either nail or hair samples after 6-week storage.

Not all the results recorded after 6-week storage was reproduced after 6 months. In agreement with the 6 week storage experiment, after 6-month storage $\delta^{13} \mathrm{C}$ analysis indicated that there was no significant difference between the samples (see Fig. 2a). However, unlike the 6-week experiment, no differences in ${ }^{15} \mathrm{~N}$ values were noted between any of the nail or hair samples after 6-month storage (see Fig. 2b). Following $\delta^{2} \mathrm{H}$ analysis, the nail sample stored in an eppendorff had a more depleted value compared to the other samples, however this shift did not exceed the natural variability expected $(10 \%$ ), as shown in Fig. 2c. Similarly, the hair samples stored in foil and the glass vial both had slightly enriched $\delta^{2} \mathrm{H}$ values compared to the remaining samples, but these differences were not greater than natural variation expected. No differences were found when analyzing the nail and hair samples for $\delta^{18} \mathrm{O}$ (Fig. 2d).

These results indicate that when carrying out $\delta^{13} \mathrm{C}, \delta^{2} \mathrm{H}$ and $\delta^{18} \mathrm{O}$ analysis of samples, the type of storage container used has little bearing upon the results obtained because of the subsequent sample preparation protocol. More pronounced and significant differences however are found when analyzing the same samples for $\delta^{15} \mathrm{~N}$, although there is no consistent isotope shift from 6 weeks to 6 months. The results suggest that the storage container of choice is a glass vial with a securely crimped lid. Paper, plastic eppendorff tubes and plastic self-seal bags should be avoided because of the possible presence of additives and plasticizers which could alter the isotopic signature of the samples to be analyzed.

\section{Conclusion}

This study has highlighted the importance of selecting the correct storage container when collecting samples for stable isotope analysis. Although this particular investigation pertains to hair and nail samples, careful selection of a storage container is essential, irrespective of the matrix to be analyzed. Although the effect of the packaging may be more pronounced for ${ }^{15} \mathrm{~N}$ than ${ }^{13} \mathrm{C},{ }^{2} \mathrm{H}$ and ${ }^{18} \mathrm{O}$, as demonstrated here, it would be good practice to conduct systematic storage experiments on a variety of commonly encountered samples that could be submitted for isotope analysis. In addition, it is essential to ensure containers are securely "crimped" or closed and that packaging containing coatings or additives are avoided to maintain the integrity of samples.

\section{Acknowledgments}

The authors wish to thank all volunteers who have kindly donated samples. Thanks are due to Nicola Farmer for assistance with instrumentation and analyses. A PhD studentship awarded to IF by the Department of Education and Learning and financial supports from ${ }^{14} \mathrm{CHRONO}$ (SPUR) and Environmental Forensics (EPSRC Platform) grants are gratefully acknowledged. 


\section{References}

1. Jasper JP, Westenberger BL, Spencer JA, Buhse LF, Nasr M. Stable isotopic characterization of active pharmaceutical ingredients. J Pharm Biomed Anal 2004;35:21-30.

2. Carter JF, Sleeman R, Hill JC, Idoine F, Titterton EL. Isotope ratio mass spectrometry as a tool for forensic investigation (examples from recent studies). Sci Justice 2005;45:141-9.

3. Reidy LJ, Meier-Augenstein W, Kalin RM. 13C-Isotope ratio mass spectrometry as a potential tool for the forensic analysis of white architectural paint: a preliminary study. Rapid Commun Mass Spectrom 2005;19:1899-905.

4. Kelly S, Heaton K, Hoogewerff J. Tracing the geographical origin of food: The application of multi-element and multi-isotope analysis. Trends Food Sci Technol 2005;16:555-67.

5. Meier-Augenstein W, Lui RH. Forensic applications of isotope ratio mass spectrometry. In: Yinon J, editor. Advances in forensic applications of mass spectrometry. U.S.A.: CRC Press, 2004;149-80.

6. Fraser I, Meier-Augenstein W, Kalin RM. The role of stable isotopes in human identification: a longitudinal study into the variability of isotopic signatures in human hair and nails. Rapid Commun Mass Spectrom 2006;20:1109-16.

7. Sharp ZD, Atudorei V, Panarello HO, Fernandez J, Douthitt C. Hydrogen isotope systematics of hair: archeological and forensic applications. J Archaeol Sci 2003;30:1709-16.

8. O'Connell TC, Hedges REM. Investigations into the effect of diet on modern human hair isotopic values. Am J Phys Anthropol 1999;108:409-25.

9. Katzenberg MA, Krouse HR. Application of stable isotope variation in human tissues to problems in identification. Can Soc Forens Sci J 1989;22:7-19.

10. Bol R, Pflieger C. Stable isotope $\left({ }^{13} \mathrm{C},{ }^{15} \mathrm{~N}\right.$ and $\left.{ }^{34} \mathrm{~S}\right)$ analysis of the hair of modern humans and their domestic animals. Rapid Commun Mass Spectrom 2002;16:2195-200.
11. Montero S, Wiarda IW, de Joode IP, Van der Peijl G. LA-ICP-MS and IRMS investigations on packaging and duct tapes [abstract]. In: Lock $\mathrm{C}$, editor. FIRMS 2005: the network developing forensic applications of stable isotope ratio mass spectrometry, March 9-10 2005; Brands Hatch, U.K. Fort Halstead, Kent: DSTL, 2005;19-20.

12. Carter JF, Grundy PL, Hill JC, Ronan NC, Titterton EL, Sleeman R. Forensic isotope ratio mass spectrometry of packaging tapes. Analyst 2004;129:1206-10.

13. http://www.plasticisers.org/index.asp?page $=3$

14. Jaegar RJ, Rubin RJ. Migration of a phthalate ester plasticizer from polyvinyl chloride blood bags into stored human blood and its localization in human tissues. N England J Med 1972;287:1114-8.

15. Racz Z, Pick J, Baroti K, Pinter J, Szabo J. Blood products stored in plastic bags: release of plasticizers from the bag material. Orv Hetil 1993;134:1581-6.

16. Bowen GJ, Chesson L, Nielson K, Cerling TE, Ehleringer JR. Treatment methods for the determination of $\delta^{2} \mathrm{H}$ and $\delta^{18} \mathrm{O}$ of hair keratin by continuous-flow isotope-ratio mass spectrometry. Rapid Commun Mass Spectrom 2005;19:2371-8.

17. Coplen TB. Normalization of oxygen and hydrogen isotope data. Chem Geol 1988;72:293-7.

Additional information and reprint requests:

Isla Fraser, B.Sc.

Environmental Forensics and Human Health

Environmental Engineering Research Centre

Queen's University Belfast

Belfast BT9 5AG

United Kingdom

E-mail: i.fraser@qub.ac.uk 